\title{
CARACTERÍSTICAS DO FRUTO DA VARIEDADE SPAN AMERICANA (Citrus reticulata Blanco): UMA TANGERINA DO TIPO 'PONCÃ' DE MATURAÇÃO PRECOCE ${ }^{1}$
}

\author{
ROSE MARY PIO ${ }^{2,4}$, KEIGO MINAMI $^{3} \&$ JOSÉ ORLANDO DE FIGUEIREDO ${ }^{2,4}$
}

\begin{abstract}
RESUMO - A tangerina-'Poncã' é bastante apreciada pelo consumidor brasileiro. No Estado de São Paulo, a maturação de seus frutos ocorre nos meses de abril a agosto. Com o mercado ávido por frutas de mesa e agravado pelo problema da ocorrência da clorose variegada dos citros (CVC), que afeta principalmente as variedades de laranjas-doces, tem havido um aumento considerável no plantio dessa variedade. Dessa forma, um excesso de produção, num mesmo período, faz com que os preços caiam, desestimulando assim os produtores. O Centro de Citricultura Sylvio Moreira (CCSM) vem buscando outras alternativas no sentido de obter, durante o ano todo, esse tipo de tangerina. Assim sendo, foram realizados estudos de caracterização de frutos, em diversas épocas do ano, com o acompanhamento dos níveis de maturação, envolvendo acessos do Banco de Germoplasma do CCSM. Dentre as variedades estudadas, quanto à precocidade e qualidade dos frutos, destacou-se a Span Americana. A tangerina-'Poncã' tem seu período de maturação para as condições edafoclimáticas do CCSM, nos meses de maio e junho. Já a variedade Span Americana, que apresenta frutos similares à 'Poncã' tradicional, tem maturação bastante precoce, podendo ser iniciada a sua colheita no mês de março.
\end{abstract}

Termos para indexação: Caracterização, fora de época, qualidade.

\section{FRUIT CHARACTERISTICS OF THE SPAN AMERICANA (Citrus reticulata Blanco): AN EARLY RIPENING 'PONKAN' LIKE MANDARIN}

\begin{abstract}
The 'Ponkan' mandarin is highly appreciated by the Brazilian consumer. In the State of São Paulo, Brazil, its fruits mature from April through August. With the market very much in demand for table fruits and due to the problem of occurrence of citrus variegated chlorosis (CVC) that affects mainly the sweet orange varieties there has been a considerable increase in planting of this variety. By this way, an over of production in a same period makes the prices drop, desistimulating the growers. The Centro de Citricultura Sylvio Moreira (CCSM) is searching other alternatives in order to obtain mandarin fruits all the year. Therefore, fruit characteristics studies in different seasons of the year with accompanying of the ripening levels, involving accesses of the germplasm bank of the CCSM, were carried out. Among the studied varieties in regard to earliness and fruit quality, the Span Americana was outstanding. The 'Ponkan' mandarin has its maturing period for the edafoclimatic conditions of the CCSM, in May and June. The Span Americana variety, that produces fruits similar to the traditional Ponkan, matures very early, and might be harvested in the beginning of March, which could be an alternative to enlarge the disponibility of mandarin fruit during the year.
\end{abstract}

Index terms: Characterization, out of season, quality.

\section{INTRODUÇÃO}

A 'Poncã' é uma das tangerinas mais populares e apreciadas pelos brasileiros para consumo in natura. Além da população brasileira, os consumidores asiáticos têm grande preferência por essa variedade. Assim sendo, as exportações para esses países vêm apresentando um leve acréscimo.

A tradicional tangerina-'Poncã' tem seu período de maturação, para as condições edafoclimáticas do Estado São Paulo, de abril, nas regiões mais quentes, até agosto, nas mais frias.

Ela também é cultivada em diversas regiões do mundo como na China, no Japão, nas Filipinas e na Índia (Saunt, 1990). Em São Paulo, essa variedade participava, no ano de 1991, com $41 \%$ do plantio, dentro do grupo das tangerineiras (Figueiredo,
1991). Segundo Amaro et al.(1997), essa porcentagem vem aumentando, sendo que ela participa, atualmente, com 59\% dentro do mesmo grupo. Com o mercado bastante ávido e receptivo para o consumo de frutas frescas aliadas ao problema da clorose variegada dos citros (CVC) que afeta, principalmente, os pomares de laranjas (Laranjeira et al., 1996), o seu plantio vem crescendo muito, o que nem sempre é bom para o produtor. É sabido que um excesso de produção, num mesmo período, faz com que os preços caiam em função de uma grande demanda.

A possibilidade de se obter tangerinas fora da safra normal trará certamente grandes benefícios para o produtor e para o consumidor que terá possibilidade de saborear esse tipo de fruto nas épocas mais quentes do ano.

Com esta finalidade, objetiva-se estudar acessos do

\footnotetext{
1 Trabalho $n^{0}$ 004/2001. Recebido: 08/01/2001. Aceito para publicação: 30/05/2001. Parte da tese de doutorado apresentada pela primeira autora a ESALQ/USP

2 Centro de Citricultura Sylvio Moreira/IAC, CP 04, 13.490-970, Cordeirópolis, SP.

3 ESALQ/USP, Departamento de Horticultura, CP 09, 13418-900, Piracicaba, SP.

4 Bolsista do CNPq
} 
Banco Ativo de Germoplasma de Citros (BAG-Citros), do Centro de Citricultura Sylvio Moreira (CCSM), do Instituto Agronômico (IAC), que apresentem características da tangerina-'Poncã' e que tenham um período de maturação fora da época quando normalmente aquela fruta não está adequada para consumo.

\section{MATERIAL E MÉTODOS}

Foi estudada a variedade Span Americana Citrus reticulata Blanco, introduzida da Córsega - França. Essa variedade, de clone nucelar, foi selecionada entre as existentes no BAG-Citros após conhecimento prévio da qualidade dos frutos.

As plantas encontram-se enxertadas em tangerina'Cleópatra' Citrus reshni Hort. ex Tan. e contavam com oito anos de plantio, no início do estudo. Elas foram conduzidas com tratos culturais rotineiros para a cultura dos citros e sem irrigação.

O Centro de Citricultura apresenta as seguintes coordenadas geográficas: $22^{\circ} 32^{\prime}$ de latitude sul e $47^{\circ} 27^{\prime}$ de longitude-oeste, altitude de $639 \mathrm{~m}$, clima do tipo Cwa, segundo a classificação de Köppen. O solo é do tipo latossolo vermelhoescuro-distrófico típico (textura argilosa). A média de precipitação pluviométrica anual é de $1.375,3 \mathrm{~mm}$. A média anual da umidade relativa do ar é de $74,2 \%$. A temperatura média anual é de $20,2^{\circ} \mathrm{C}$, sendo a média das máximas igual a $27,5^{\circ} \mathrm{C}$ e a média das mínimas igual a $14,5^{\circ} \mathrm{C}$ (Tabela 1 ).

Para a coleta dos frutos que formaram as amostras, foram utilizadas as três árvores existentes no BAG. Foram colhidos dez frutos por árvore, num total de 30 . Tais frutos foram coletados na porção externa da copa, na faixa compreendida entre 1,0 e $2,0 \mathrm{~m}$ do solo e em toda a extensão do perímetro da planta. Iniciada a coleta, ela se repetiu a cada mês, entre março e junho. Os estudos foram realizados em três anos consecutivos (1994, 1995 e 1996).

As determinações de altura e diâmetro do fruto foram feitas por leitura direta de cada amostra, com o auxílio de uma escala graduada em centímetros. As avaliações das colorações de casca e suco foram baseadas em Biesalski (1957). O peso total dos frutos de cada amostra foi obtido, de uma só vez, em uma balança, marca Filizola, com capacidade de até $15 \mathrm{~kg}$, com sensibilidade de $5 \mathrm{~g}$. As características morfológicas (forma do fruto, ápice e base) foram baseadas no Descriptors for Citrus (IBPGR, 1988).

O rendimento de suco foi determinado após esmagamento do fruto na extratora OIC modelo OTTO 1800 (filtro com diâmetro interno $=26,11 \mathrm{~mm}$, comprimento $=265 \mathrm{~mm}$, furos de diâmetro $=0,6 \mathrm{~mm}$, área de vazão $=20 \%$ ) e calculado através da relação peso do suco/peso do fruto e expresso em porcentagem. O número de sementes foi obtido pela contagem em cinco frutos, no ano de 1996. O teor de sólidos solúveis totais (brix ou SST) foi determinado por leitura direta no refratômetro B\&S, modelo RFM 330. Os dados foram corrigidos pela temperatura e pela acidez do suco. A acidez total (AT) foi obtida por titulação de $25 \mathrm{ml}$ de suco, com uma solução de hidróxido de sódio de normalidade de 0,3125 e usando-se a fenolftaleína como indicadora. Foi calculada a relação sólidos solúveis : acidez (ratio ou SST:AT), fazendo-se o valor da acidez igual a 1.Essa relação indica o estádio de maturação dos frutos cítricos.
O índice tecnológico (IT), segundo Di Giorgi et al.(1990), foi obtido pela equação:

IT $=\quad$ Rendimento em suco $\mathrm{x}$ sólidos solúveis $\mathrm{x} 40,8$

$$
10.000
$$

onde:

$->\mathrm{IT}=$ índice tecnológico

-> Rendimento em suco = relação peso do suco e peso do fruto

-> Sólidos Solúveis $=$ teor de sólidos solúveis

-> 40,8 kg = peso padrão da caixa de colheita de laranja

Foram calculadas as médias e os desvios-padrão da variedade estudada, nos três anos da realização do estudo (1994, 1995 e 1996).

\section{RESULTADOS E DISCUSSÃO}

O estudo da variedade permitiu a confecção de uma ficha pomológica que será apresentada a seguir.

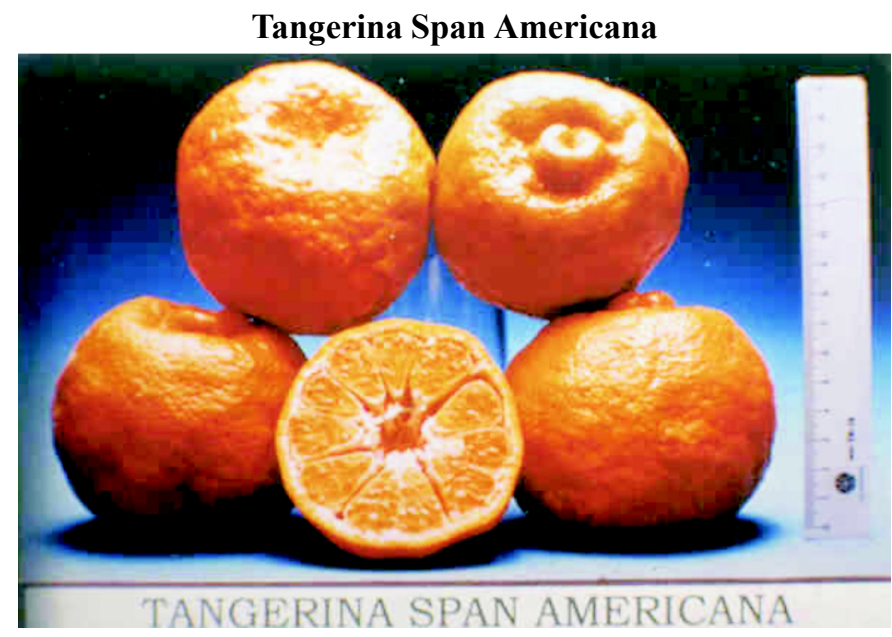

Foi introduzida da Córsega, no ano de 1967. Apresenta frutos de tamanho grande, de coloração amarelo-alaranjada, forma oblata. Casca ligeiramente rugosa com glândulas de óleo proeminentes. Ápice deprimido e base côncava com colarinho e pescoço. Peso médio de 162g. Polpa de cor alaranjada forte com aspecto granuloso, 11 sementes por fruto em média. Suco correspondendo a $37 \%$ do peso do fruto, com teores médios de brix de $11,5 \%$; acidez de $0,6 \%$ e ratio de 18,2 . O índice tecnológico corresponde a 1,6 kg de sólidos solúveis/caixa. Seus frutos podem ser colhidos a partir do início do mês de março.

Na Tabela 2, encontram-se os dados médios obtidos de altura e diâmetro dos frutos da variedade estudada, em centímetros, nos anos de 1994, 1995 e 1996. Pode-se verificar que os dados variaram de 5,2 a $8,0 \mathrm{~cm}$ para a altura e de 5,7 a $8,2 \mathrm{~cm}$ para o diâmetro. Esses resultados, para essas características, são bastante satisfatórios, tendo em vista que o consumidor brasileiro tem preferência por frutos de maior tamanho. Esse tipo de preferência também se dá com os asiáticos, que são alvos de exportação da fruta brasileira.

Com relação aos valores médios de peso dos frutos, expressos em gramas, a variedade destacou-se por apresentar, no ano de 1994, 194,5g e 1995, 210,2g. Segundo Figueiredo 
TABELA 1- Dados climáticos mensais do Centro de Citricultura Sylvio Moreira, Cordeirópolis/SP, no período de 1940 a 1989.

\begin{tabular}{|c|c|c|c|c|c|c|}
\hline M ês & $\begin{array}{l}\mathrm{R} \text { ad. S o la r } \\
\text { c a l.c m }{ }^{2} \\
\text { dia }\end{array}$ & $\begin{array}{l}\text { T e m p. } \\
\mathrm{m} \mathrm{áx} \mathrm{i} \mathrm{m} \mathrm{a} \\
{ }^{\circ} \mathrm{C}\end{array}$ & $\begin{array}{l}\mathrm{T} \text { e m p . } \\
\mathrm{m} \text { ín im a } \\
{ }^{\circ} \mathrm{C}\end{array}$ & $\begin{array}{l}\text { Tem p.m ín. } \\
\text { a b s o luta } \\
{ }^{\circ} \mathrm{C}\end{array}$ & $\begin{array}{c}\mathrm{C} \mathrm{huva} \\
\mathrm{m} \mathrm{m}\end{array}$ & $\begin{array}{c}\mathrm{U} \mathrm{m} \text { id a d e } \\
\text { re lativa } \\
\%\end{array}$ \\
\hline Janeiro & 506 & 29,1 & 17,8 & 11,2 & 235 & 80 \\
\hline Fevereiro & 507 & 29,2 & 18,0 & 10,9 & 195 & 81 \\
\hline Março & 479 & 28,9 & 17,1 & 9,8 & 164 & 79 \\
\hline Abril & 435 & 27,5 & 14,8 & 3,2 & 68 & 77 \\
\hline Maio & 357 & 25,4 & 12,4 & 0,3 & 55 & 76 \\
\hline Junho & 322 & 24,5 & 11,2 & $-1,5$ & 40 & 74 \\
\hline Julho & 347 & 24,7 & 10,6 & $-1,2$ & 27 & 70 \\
\hline Agosto & 403 & 26,9 & 12,0 & $-0,5$ & 30 & 64 \\
\hline Setembro & 444 & 28,0 & 13,3 & $-1,2$ & 64 & 65 \\
\hline Outubro & 492 & 28,2 & 14,9 & 2,9 & 12 & 72 \\
\hline Novembro & 529 & 28,5 & 15,8 & 7,0 & 151 & 75 \\
\hline Dezembro & 491 & 28,6 & 17,0 & 9,5 & 229 & 78 \\
\hline
\end{tabular}

Fonte: ORTOLANI et al., 1991

TABELA 2 - Média e desvio-padrão dos dados das características do fruto da tangerina Span Americana do BAG-Citros do IAC/ Cordeirópolis (SP), nos anos de 1994, 1995 e 1996.

\section{C a racterísticas}

do fruto

1994

1995

1996

\begin{tabular}{|c|c|c|c|}
\hline Altura (cm) & $6,7 \pm 0,1$ & $8,0 \pm 0,2$ & $5,2 \pm 0,4$ \\
\hline D iâ m e tro (c m ) & $8,1 \pm 0,3$ & $8,2 \pm 0,4$ & $5,7 \pm 0,1$ \\
\hline P e so (g) & $194,5 \pm 21,4$ & $210,2 \pm 10,4$ & $83,2 \pm 8,0$ \\
\hline S u co $(\%)$ & $41,3 \pm 3,6$ & $30,0 \pm 3,2$ & $40,0 \pm 2,7$ \\
\hline $\mathrm{N}{ }^{\circ} \mathrm{sem}$ entes & - & - & $11,8 \pm 1,7$ \\
\hline$B \operatorname{rix}(\%)$ & $10,8 \pm 1,0$ & $12,2 \pm 1,3$ & $11,7 \pm 0,3$ \\
\hline A cide z $(\%)$ & $0,6 \pm 0,1$ & $0,4 \pm 0,0$ & $0,8 \pm 0,1$ \\
\hline$R$ a tio & $17,4 \pm 3,6$ & $24,3 \pm 6,3$ & $13,0 \pm 1,9$ \\
\hline B rix ( $\mathrm{kg} / \mathrm{c} a \mathrm{ix} a)$ & $1,6 \pm 0,3$ & $1,4 \pm 0,1$ & $1,8 \pm 0,2$ \\
\hline
\end{tabular}

TABELA 3 - Dados da variação de teores de brix, acidez e ratio da tangerina Span Americana, do BAG - Citros, do IAC/Cordeirópolis (SP), nos anos de 1994, 1995 e 1996, com as respectivas médias e desvios-padrão.

\begin{tabular}{|c|c|c|c|c|c|c|c|c|c|c|c|c|c|c|c|c|c|c|c|c|}
\hline \multirow[t]{2}{*}{ Período } & \multicolumn{6}{|c|}{1994} & \multicolumn{7}{|c|}{1995} & \multicolumn{7}{|c|}{1996} \\
\hline & $28 / 3$ & $25 / 4$ & $28 / 5$ & $20 / 6$ & MD 94 & DP 94 & $12 / 04$ & $29 / 05$ & $19 / 06$ & $09 / 07$ & MD95 & DP95 & $24 / 03$ & $22 / 04$ & $10 / 05$ & $24 / 06$ & $08 / 07$ & $22 / 08$ & MD 96 & DP 96 \\
\hline Brix & 9,8 & 10,2 & 11,2 & 12,1 & 10,8 & 1,0 & 10,8 & 11,7 & 12,6 & 14,0 & 12,2 & 1,3 & 11,1 & 11,5 & 12,2 & 11,9 & 11,7 & 11,8 & 11,7 & 0,3 \\
\hline Acidez & 0,8 & 0,5 & 0,6 & 0,5 & 0,6 & 0,1 & 0,6 & 0,5 & 0,4 & 0,4 & 0,4 & 0,0 & 1,0 & 0,9 & 1,0 & 0,7 & 0,7 & 0,8 & 0,8 & 0,1 \\
\hline Ratio & 12,2 & 18,4 & 18,0 & 21,0 & 17,4 & 3,6 & 16,7 & 22,1 & 27,2 & 31,5 & 24,3 & 6,3 & 10,7 & 12,4 & 11,5 & 15,2 & 15,4 & 13,2 & 13,0 & 1,9 \\
\hline
\end{tabular}

(1991), o peso médio dos frutos da tangerina-'Poncã' é de $138 \mathrm{~g}$. A variedade Span Americana apresentou valores superiores aos da Poncã, nos anos de 1994 e 1995, e somente em 1996, esse dado adquiriu valor menor $(83,2 \mathrm{~g})$. Essa redução no tamanho do fruto pode ter sido devida às condições meteorológicas ocorridas por ocasião de seu crescimento (Tabela 4) ou mesmo por um excesso de produção neste ano. Para este caso, a prática de raleio constitui técnica apropriada para atingir o tamanho de fruto desejado.
A coloração da casca dos frutos, segundo Biesalski (1957), correspondeu ao código 3:7:1,5 (cor amarelo-alaranjada). Essa coloração de casca também é encontrada para a tradicional 'Poncã', segundo Figueiredo (1991). De maneira geral, as variedades de tangerinas e híbridos que obtêm uma coloração de casca alaranjada apresentam uma melhor aceitação pelo público consumidor, o que ocorre normalmente com a tangerina'Poncã'. Variedades que possuem coloração dos frutos mais avermelhada no ponto ideal de maturação causam a impressão 
TABELA 4 - Dados climáticos mensais referentes ao Centro de Citricultura Sylvio Moreira, Cordeirópolis/ SP, no período de 1993 a 1996, fornecidos pelo Centro de Ecofisiologia e Biofísica, do Instituto Agronômico, Campinas (SP).

\begin{tabular}{|c|c|c|c|c|c|c|c|c|c|c|c|c|c|}
\hline $\mathrm{Ano} / \mathrm{M}$ ês & JA N & FE V & M A R & A B R & M A IO & $\mathrm{JUN}$ & JUL L & $\mathrm{AGO}$ & SET & $\mathrm{OUT}$ & $\mathrm{NOV}$ & DEZ & $\mathrm{ANO}$ \\
\hline \multicolumn{14}{|c|}{ Chuva Freqüência } \\
\hline 1993 & 19 & 25 & 10 & 4 & 4 & 6 & 1 & 3 & 13 & 12 & 8 & 19 & 124 \\
\hline 1994 & 13 & 14 & 10 & 7 & 6 & 6 & 3 & 0 & 0 & 11 & 11 & 15 & 96 \\
\hline 1995 & 19 & 20 & 12 & 7 & 8 & 3 & 5 & 1 & 5 & 11 & 10 & 13 & 114 \\
\hline 1996 & 17 & 17 & 18 & 8 & 8 & 3 & 2 & 4 & 11 & 10 & 11 & & 109 \\
\hline \multicolumn{14}{|c|}{ Total de Chuva $(\mathrm{mm})$} \\
\hline 1993 & 297,6 & 316,6 & 85,0 & 66,8 & 59,0 & 52,7 & 9,0 & 22,7 & 194,9 & 104,0 & 98,9 & 198,4 & 1505,6 \\
\hline 1994 & 153,6 & 158,9 & 102,7 & 51,1 & 54,3 & 47,3 & 20,5 & 0,0 & 0,0 & 96,9 & 244,4 & 248,3 & 1178,0 \\
\hline 1995 & 282,7 & 427,2 & 146,9 & 242,2 & 35,6 & 22,8 & 40,8 & 1,2 & 37,2 & 145,3 & 130,4 & 210,0 & 1722,3 \\
\hline 1996 & 340,7 & 169,0 & 198,7 & 58,4 & 49,7 & 19,9 & 1,4 & 55,0 & 171,5 & 148,1 & 274,3 & - & 1486,7 \\
\hline \multicolumn{14}{|c|}{ Temperatura $M$ édia $[(\mathrm{T} m a x+T m i n) / 2]$} \\
\hline 1993 & 24,0 & 22,7 & 23,7 & 21,9 & 18,9 & 17,3 & 18,2 & 16,9 & 19,6 & 21,9 & 21,8 & 23,4 & 21,5 \\
\hline 1994 & 22,9 & 25,2 & 22,7 & 21,4 & 20,0 & 16,9 & 18,7 & 19,1 & 22,1 & 22,7 & 21,4 & 21,0 & 21,1 \\
\hline 1995 & 26,4 & 23,5 & 23,2 & 21,2 & 18,9 & 18,4 & 19,6 & 21,4 & 21,5 & 21,8 & 23,5 & 23,3 & 20,2 \\
\hline 1996 & 24,2 & 24,5 & 23,6 & 21,9 & 18,2 & 17,7 & 16,6 & 19,9 & 20,1 & 20,0 & 22,0 & 21,4 & 21,4 \\
\hline
\end{tabular}

ao consumidor de fruto em estádio de "passado".

A alta porcentagem de suco é uma característica bastante interessante para as variedades cítricas, tanto para aquelas que serão utilizadas para consumo in natura como para a industrialização. Considerando que na tangerina-'Poncã', o suco corresponde a $43 \%$ do peso do fruto (Figueiredo, 1991), a variedade Span Americana apresentou valores que variaram de 30,0 a $41,3 \%$. Portanto, valores pouco abaixo dos encontrados para a 'Poncã' tradicional.

O pequeno número de sementes é um fator importante para os frutos das variedades cítricas que serão consumidas in natura. Na Tabela 2, são apresentados os valores médios do número de sementes da variedade Span Americana, no ano de 1996. Considerando que a 'Poncã' possui em média cinco a oito sementes por fruto, a variedade aqui estudada apresentou 11,8 sementes/fruto (média de um ano). Cabe ressaltar que a variedade estudada encontra-se no Banco Ativo de Germoplasma, onde ocorre naturalmente polinização cruzada entre as diversas espécies e variedades ali existentes, o que poderá aumentar consideravelmente o número de sementes por fruto.

Segundo Figueiredo (1991), para as cultivares plantadas comercialmente no Estado de São Paulo, o brix varia de 10,4\% para a mexerica do 'Rio'; $10,8 \%$ para as tangerinas-'Poncã' e 'Cravo' e 12,8\% para o tangor 'Murcott'. Observando a Tabela 2 , os valores médios de brix alcançados para a Span Americana foram de 10,8\%, em 1994; 12,25, em 1995 e 11,7\%, em 1996. Em média, alcançou valores bastante apropriados para o paladar do consumidor brasileiro.

Os valores médios de acidez obtidos são mostrados na Tabela 2. Para as variedades comerciais, a porcentagem de acidez varia da seguinte maneira: $0,99 \%$ para a mexerica do 'Rio'; $0,85 \%$ para a tangerina-'Poncã'; $0,92 \%$ para o tangor 'Murcott' e $0,80 \%$ para a tangerina- 'Cravo'(Figueiredo, 1991). Os valores médios de acidez obtidos pela tangerina Span Americana variaram de 0,4 (em 1995) a $0,8 \%(\mathrm{em} \mathrm{1996)}$.

O ratio constitui uma característica bastante importante para as variedades cítricas, indicando o ponto de maturação dos frutos.

As variedades cultivadas comercialmente no Estado de São Paulo apresentam os seguintes valores de ratio: mexerica do 'Rio, 10,5; tangerina-'Poncã', 12,7; tangor-'Murcott' e tangerina-'Cravo', 13,5 (Figueiredo, 1991). A variedade aqui estudada mostrou, de maneira geral, valores de ratio adequados para consumo in natura (17,4, em 1994; 24,3, em 1995 e 13,0, em 1996). No ano de 1995, o valor tornou-se bastante alto devido aos baixos valores de acidez $(0,4 \%)$. De acordo com a Tabela 4 , não ocorreram grandes modificações nos dados meteorológicos que pudessem interferir no processo de maturação dos frutos; entretanto, algum fator contribuiu para a queda bastante acentuada da acidez, acarretando um aumento considerável do ratio.

O teor de sólidos solúveis, expresso em $\mathrm{kg} / \mathrm{caixa}$ de laranja $(40,8 \mathrm{~kg})$ é um parâmetro que vem adquirindo muita importância, principalmente quando a variedade se presta para a industrialização.

As variedades utilizadas comercialmente com essa finalidade, como as laranjas 'Hamlin', 'Pêra', 'Natal' e 'Valência', apresentam valores médios de sólidos solúveis $(\mathrm{kg} /$ caixa) entre 2,2 e 2,7 (Di Giorgi et al., 1990).

$O$ rendimento de brix/caixa da variedade Span Americana atingiu valores que variaram de 1,4 a 1,8kg/caixa. Esses valores encontrados estão abaixo dos normalmente conseguidos pelas laranjas utilizadas com finalidade industrial. Cabe lembrar que os frutos da tangerina-'Poncã' também são processados quando há um excedente de safra.

Nas condições edafoclimáticas do Centro de Citricultura, em Cordeirópolis-SP, onde a variedade foi estudada, a 'Poncã' tradicional tem seu período de maturação nos meses de maio a junho. A tangerina Span Americana alcança valores de ratio bastante adequados no início do mês de março e certamente poderão ser colhidos no mês de fevereiro, nas regiões mais quentes do Estado de São Paulo. Deve-se ressaltar que, para esse estudo, as plantas se encontravam enxertadas em tangerina- 'Cleópatra'. Para uma melhoria na antecipação da safra, 
a enxertia dessa variedade deverá ser realizada em limão-'Cravo', o que certamente aumentará essa precocidade. Esse fato vem ocorrendo nos ensaios regionais onde esse germoplasma tem sido testado e vem motivando produtores de regiões com temperaturas mais elevadas a procurarem essa tangerina do tipo 'Poncã'.

\section{CONCLUSÕES}

1. Os frutos da tangerina Span Americana apresentam características de sabor e forma bastante semelhantes aos da 'Poncã' tradicional.

2. O tamanho e a coloração estão bem adequados ao gosto do consumidor brasileiro.

3. Seus frutos podem ser colhidos com dois meses de antecedência, propiciando a antecipação da comercialização dessa variedade no mercado de fruta fresca.

\section{REFERÊNCIAS BIBLIOGRÁFICAS}

AMARO, A .A .; MAIA, M. L. Produção e comércio de laranja e de suco no Brasil. Laranja, Cordeirópolis, v.18, n.1,p.1-26, 1997.

BIESALSKI, E. Pflanzenfarben-Atlas für Gartenbau Landwirtschaft und Fortwesen mit Farbezeichen nach DIN 6164, Berlin, 1957. n.p.
DI GIORGI, F.; IDE, B.Y.; DIB, K.; MARCHI, R.J.; TRIONI, H. DE R.; WAGNER, R.L. Contribuição ao estudo do comportamento de algumas variedades de citros e suas implicações agroindustriais. Laranja, Cordeirópolis, v.11, p.567-612, 1990.

FIGUEIREDO, J.O. DE. Variedades copa de valor comercial. In: RODRIGUEZ, O.; VIÉGAS, F.; POMPEU JUNIOR, J.; AMARO, A.A. (Ed.) Citricultura brasileira. 2.ed.Fundação Campinas: Cargill. 1991. v.1., p.228-264.

IBPGR. Descriptors for Citrus. Rome: Int. Board Plant Genetic Resour. Secretariat, 1988. 27p.

LARANJEIRA, F.F.; HARAKAVA, R.; CARVALHO, S.A .; POMPEU JUNIOR, J.; FIGUEIREDO, J.O. DE. Avaliação serológica da ocorrência de Xylella fastidiosa e clorose variegada dos citros (CVC) no Banco Ativo de Germoplasma do IAC. Fitopatologia brasileira, Suplemento, v. 21, p.335, 1996.

ORTOLANI, A.A.; PEDRO JUNIOR, M.; ALFONSI, R.R. Agroclimatologia e o cultivo dos citros. In: RODRIGUEZ, O.;VIÉGAS, F.; POMPEU JUNIOR, J.; AMARO, A.A. (Ed.) Citricultura brasileira. 2.ed. Campinas: Fundação Cargill, 1991. v.1., p.153-185.

SAUNT, J. Citrus varieties of the world: an illustrade guide. Norwick, Sinclair International, 1990. 128p. 